RASĀYAN J. Chem.

Vol. 12 | No. 4 |1681 - 1687| October - December | 2019 ISSN: 0974-1496 | e-ISSN: 0976-0083 | CODEN: RJCABP

RJC http://www.rasayanjournal.com http://www.rasayanjournal.co.in

\title{
OXIDATION OF POLYETHYLENE GLYCOL-200 BY POTASSIUM PERIODATE IN ALKALINE MEDIUM: A KINETIC STUDY
}

\author{
K. V. S. Koteswara Rao ${ }^{1}$ and R. Venkata $\mathrm{Nadh}^{2, *}$ \\ ${ }^{1}$ Department of Chemistry, GVSM Government Degree College, Ulavapadu-523292, India \\ ${ }^{2}$ GITAM University - Bengaluru Campus, Karnataka - 561203, India \\ *E-mail: venkatanadh.ratnakaram@gitam.edu
}

\begin{abstract}
Kinetics of PEG-200 oxidation by potassium periodatewas studied in alkaline medium. First-order dependence of reaction on periodate was observed. Rate of the reaction was found to be independent of substrate concentration. An inverse fractional order with respect to alkaliwas shown. Arrhenius parameters were calculated. Rate law was postulated taking into consideration of experimental results.

Keywords: Kinetics, Oxidation, Polyethylene Glycol, Potassium Periodate, Alkaline Medium
\end{abstract}

(C) RASĀYAN. All rights reserved

\section{INTRODUCTION}

Polyethylene Glycols (PEGs) having different molecular weights (MW) are used in drug delivery systems. ${ }^{1}$ PEGs (200to 8,000,000)arebroadly used in cosmetics. ${ }^{2}$ PEG 200 to PEG 600 are liquid PEGs and they are used as water-miscible solubilizers in parenteral as well as oral liquids. As per the US FDA's Inactive Ingredient Guide (IIG), PEG-200 is used in the delivery of drugs in injection dosage forms. ${ }^{3}$ Study of reaction rate constants is useful for investigation of reaction mechanism and to derivate laws for describing the reaction characteristics. In addition to inorganic oxidants like cerium(IV) ${ }^{5}$ and vanadium $(\mathrm{V})^{6}$, N-halo oxidants like $\mathrm{NBS}^{7,8}, \mathrm{DCICA}^{9-12}, \mathrm{DCQCI}^{13,14}, \mathrm{CAT}^{15}$ were well usedin the kinetic studies.

Study of oxidation of different types of substituted alcohols is the interest of many researchers. ${ }^{78,15}$ Oxidation of PEG by ceric (IV) ions ${ }^{16,17}$ and Fenton ${ }^{18-20}$ was well studied.Free radicals are involved in the oxidation of PEG by Ce(IV), though the mechanism involvedin it is not completely known. ${ }^{16}$ The radical mechanism was proposed in the oxidation of PEG in the presence of catalytic activity of $\mathrm{Mn} / \mathrm{Ce}$ composite oxide. ${ }^{21}$ Oxidation by Jone's reagent resulted in high yields of poly(oxyethylene)-dicarboxylic acids at room temperature. ${ }^{22}$ Uncatalyzed and $\mathrm{Ru}(\mathrm{III})$ catalyzed oxidation in the presence of permanganate was studied byHassan et al. ${ }^{23}$ In view of wide industrial 'usage of PEG-200, kinetic study of oxidation by periodate in aqueous alkaline medium was carried out.

\section{EXPERIMENTAL}

Analytical grade reagents were used during the present study. Iodometry was used to follow the kinetics of the reaction. Loss of one oxygen atom or transfer of two electrons was observed per each molecule of periodate in the oxidation of PEG-200. It means, followed the oxidation capacity of periodatetill it is converted into iodate ${ }^{5}$.

\section{RESULTS AND DISCUSSION}

Reaction Orders of Oxidant, Substrate, and Alkali

The concentration of the oxidant (periodate) waschanged in the range of 0.00025 to $0.002 \mathrm{M}$ while maintaining constant concentration for each of other reactants (Table-1). First-order reaction w.r.t. [periodate] was evident from linearity of the curves (up to $85 \%$ of reactions) in the graphs of $\log (\mathrm{a}-\mathrm{x}$ ) Rasayan J. Chem., 12(4), 1681-1687(2019)

http://dx.doi.org/10.31788/RJC.2019.1245433

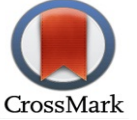


RASĀYAN J. Chem.

Vol. 12 | No. 4 |1681 - 1687| October - December | 2019

versus time (Fig.-1). The same was confirmed from fairly constant values of rate constant in the studied range of [oxidant].

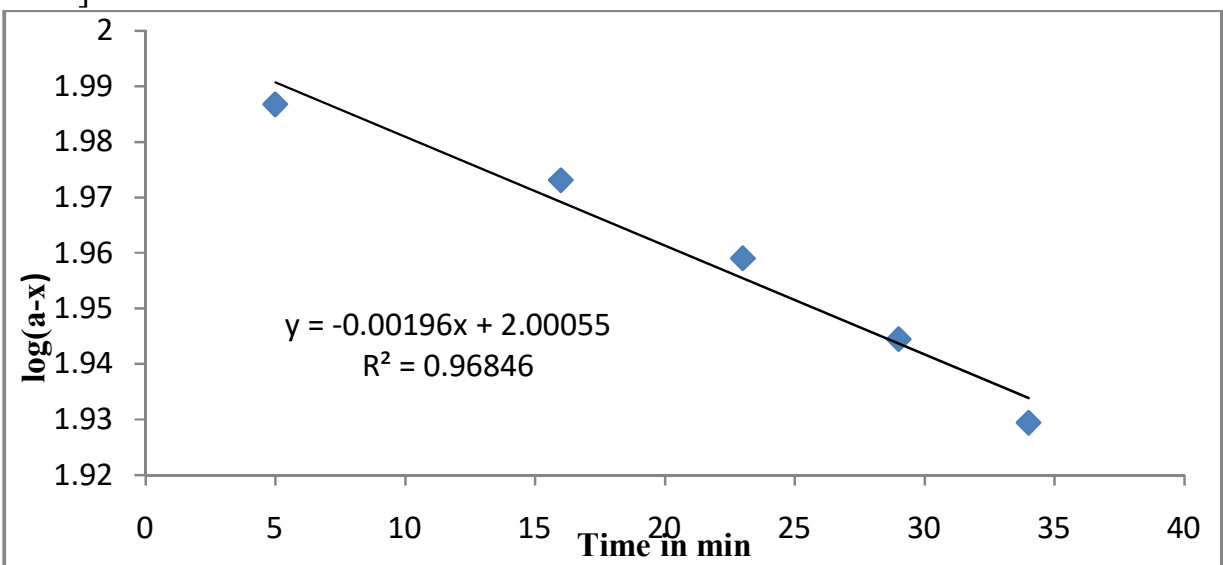

Fig.-1:Plot of $\log (\mathrm{a}-\mathrm{x})$ versus time at $\left[\mathrm{KIO}_{4}\right]=0.001 \mathrm{M},[\mathrm{PEG}-200]=0.025 \mathrm{M}$,

$\left[\mathrm{OH}^{-}\right]=0.1 \mathrm{M}$ and Temperature $=35^{\circ} \mathrm{C}$

Substrate inhibition was reported in the literature for the oxidation of sugar alcohols ${ }^{24,25}$ by $\mathrm{KIO}_{4}$ in alkaline medium. But, in the present case, zero-order in [substrate] was noted as no appreciable change in rate constant was observed when the [PEG-200] was varied from 0.0025 to $0.1 \mathrm{M}$.

Table-1: Oxidation of PEG-200by Potassium Periodate in An Alkaline Medium

\begin{tabular}{|c|c|c|c|c|}
\hline & Variant & $\begin{array}{l}\text { Conc. of Variant } \\
\text { (M) }\end{array}$ & $\mathrm{k}_{1} \times 10^{4} \min ^{-1}$ & \\
\hline & \multirow{4}{*}{ [Periodate] } & 0.00025 & 47.04 & \\
\hline & & 0.0005 & 46.97 & \\
\hline & & 0.001 & 45.14 & \\
\hline & & 0.002 & 44.19 & \\
\hline & \multirow{5}{*}{ [PEG-200] } & 0.0025 & 47.07 & \\
\hline & & 0.0125 & 45.77 & \\
\hline & & 0.025 & 46.97 & \\
\hline & & 0.05 & 46.78 & \\
\hline & & 0.1 & 45.56 & \\
\hline & \multirow{4}{*}{ [Alkali] } & 0.05 & 58.60 & \\
\hline & & 0.1 & 46.97 & \\
\hline & & 0.2 & 34.52 & \\
\hline & & 0.5 & 21.42 & \\
\hline & \multirow{5}{*}{ Salt } & 0 & 46.97 & \\
\hline & & $\mathrm{KCl}$ & 31.19 & \\
\hline & & $\mathrm{KBr}$ & 49.76 & \\
\hline & & $\mathrm{KI}$ & 2.16 & \\
\hline & & $\mathrm{KNO}_{3}$ & 45.95 & \\
\hline & \multirow{4}{*}{ [Boric Acid] } & 0 & 46.97 & \\
\hline & & 0.01 & 47.10 & \\
\hline & & 0.025 & 47.91 & \\
\hline & & 0.05 & 48.79 & \\
\hline & \multirow{4}{*}{ Temperature } & 35 & 46.97 & \\
\hline & & 40 & 85.81 & \multirow{6}{*}[\mathrm{OH}^{-}]{$=0.1 \mathrm{M}$} \\
\hline & & 45 & 124.36 & \\
\hline & & 50 & 181.23 & \\
\hline \multirow[t]{3}{*}[\mathrm{KIO}_{4}]{$=0.0005 \overline{\mathrm{N}}$} & \multirow{3}{*}[\text{Salt}]{} & $G-200]=0.025 \mathrm{~N}$ & & \\
\hline & & $0.1 \mathrm{M}$ Temper & $=35^{\circ} \mathrm{C}$ & \\
\hline & & 1682 & & \\
\hline
\end{tabular}


RASĀYAN J. Chem.

Vol. 12 | No. 4 |1681 - 1687| October - December | 2019

Rate of the reaction was decreased when hydroxide concentrationwas increased from 0.05 to 0.5 M.The order of reaction w.r.t. [alkali] was found to beinverse fractional-order as the slope of $\log \mathrm{k}_{1} \mathrm{vs} \log \left[\mathrm{OH}^{-}\right]$ plot was -0.44 (Fig.-2).

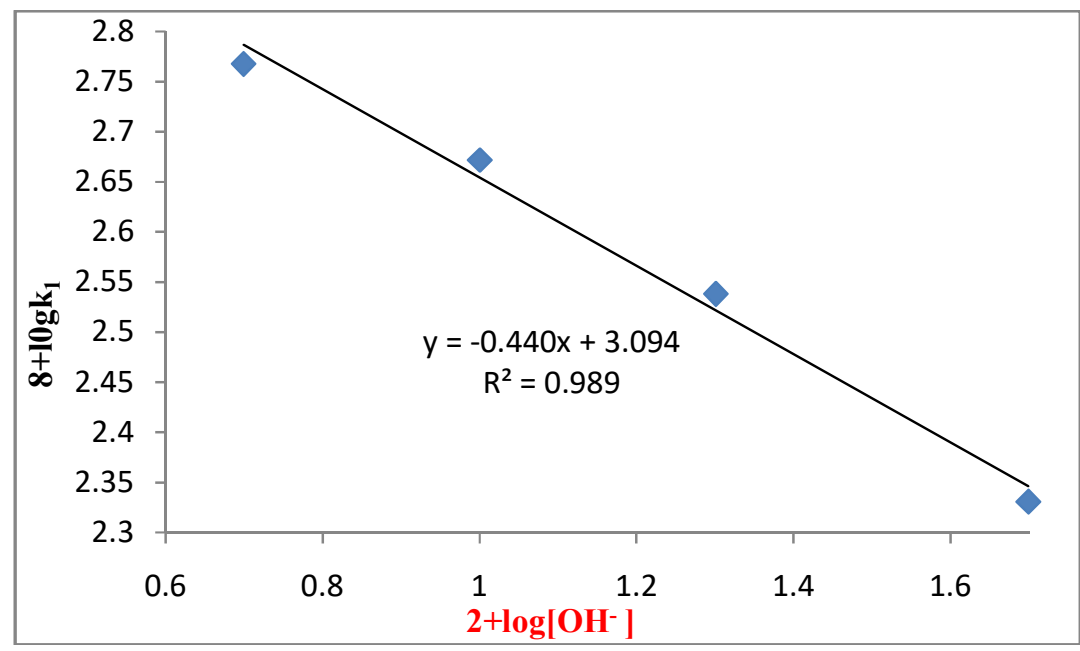

Fig.-2: Effect of Alkali Concentration on Oxidation of PEG-200 by Periodate

As per Aveston $^{26}$, potassiumperiodate dissociates in alkaline medium and establishequilibria(1-3) as shown below along with the respective equilibrium constants measured at $298.2 \mathrm{~K}$.

$$
\begin{array}{lr}
2 \mathrm{IO}_{4}^{-}+2 \mathrm{OH}^{-} \rightleftharpoons \mathrm{H}_{2} \mathrm{I}_{2} \mathrm{O}_{10}^{4-} & \log K_{1}=15.05 \\
\mathrm{IO}_{4}^{-}+\mathrm{OH}^{-}+\mathrm{H}_{2} \mathrm{O} \underset{\mathrm{H}}{\rightleftharpoons} \mathrm{I}_{6}^{2-} & \log \mathrm{K}_{2}=6.21 \\
\mathrm{IO}_{4}^{-}+2 \mathrm{OH}^{-} \rightleftharpoons \mathrm{H}_{2} \mathrm{IO}_{6}^{3-} & \log \mathrm{K}_{3}=8.67
\end{array}
$$

The above equilibria are useful for calculation of the extent of species distribution in aqueous alkaline solution. The concentrations of the two species $\left(\mathrm{IO}_{4}^{-}\right.$and $\left.\mathrm{H}_{2} \mathrm{I}_{2} \mathrm{O}_{10}^{4-}\right)$ are negligible in the used range of hydroxide ion concentration. Hence, the remaining key species are $\mathrm{H}_{3} \mathrm{IO}_{6}^{2-} \mathrm{andH}_{2} \mathrm{IO}_{6}^{3-}$. Their concentrations are calculated using Crouthamel's data ${ }^{27}$, which also corroborates with the findings of others. ${ }^{28-30}$ As per Shan ${ }^{29}$, the above equilibria (2) and (3) results in the following two equations (4) and (5).

$$
\begin{aligned}
& \mathrm{H}_{2} \mathrm{IO}_{6}^{3-}=\frac{\beta_{3}\left[\mathrm{OH}^{-}\right]^{2}}{1+\beta_{2}\left[\mathrm{OH}^{-}\right]+\beta_{3}\left[\mathrm{OH}^{-}\right]^{2}}\left[\mathrm{IO}_{4}^{-}\right]_{\mathrm{ex}}=f\left(\left[\mathrm{OH}^{-}\right]\right)\left[\mathrm{IO}_{4}^{-}\right]_{\mathrm{ex}} \\
& \mathrm{H}_{3} \mathrm{IO}_{6}^{2-}=\frac{\beta_{2}\left[\mathrm{OH}^{-}\right]}{1+\beta_{2}\left[\mathrm{OH}^{-}\right]+\beta_{3}\left[\mathrm{OH}^{-}\right]^{2}}\left[\mathrm{IO}_{4}^{-}\right]_{\mathrm{ex}}=\varnothing\left(\left[\mathrm{OH}^{-}\right]\right)\left[\mathrm{IO}_{4}^{-}\right]_{\mathrm{ex}}
\end{aligned}
$$

Here $\left[\mathrm{IO}_{4}^{-}\right]_{e x}$ denotes the concentration of the original overall periodate ion and it is nearly equivalent to the summation of concentrations of $\mathrm{H}_{2} \mathrm{IO}_{6}^{3-}$ and $\mathrm{H}_{3} \mathrm{IO}_{6}^{2-}$. Table- 2 gives the concentrations of the two important periodate species $\left(\mathrm{H}_{2} \mathrm{IO}_{6}^{3-}\right.$ and $\left.\mathrm{H}_{3} \mathrm{IO}_{6}^{2-}\right)$ at different concentrations of alkali ranging from 0.025 to $0.5 \mathrm{M}$. Values of the Table-2 show that $\mathrm{H}_{2} \mathrm{IO}_{6}^{3-}$ and $\mathrm{H}_{3} \mathrm{IO}_{6}^{2-}$ are the principal species at higher and lower concentrations of alkali respectively. Hence, PEG-200 can complex with one of these two species.

\section{Effect of Temperature}

An increase in the first-order rate constants $\left(\mathrm{k}_{1}\right)$ was observed by increasing the temperature in the range of 35 to $50^{\circ} \mathrm{C}$.A straight line was yielded by plotting $\log \left(\mathrm{k}_{1}\right)$ vs. 1/T (Fig. -3 ). The slope of the plot and Eyring equation ${ }^{32}$ were used to calculate the activation parametervalues. The activation energy $\left(\boldsymbol{\Delta} \mathbf{E}^{\neq}\right)$, 
RASĀYAN J. Chem.

Vol. 12 | No. 4 |1681 - 1687| October - December | 2019

Enthalpy of activation $\left(\Delta \mathbf{H}^{\neq}\right)$,Gibb's free energy $\left(\Delta \mathbf{G}^{\neq}\right)$andentropy of activation $\left(-\boldsymbol{\Delta} \mathbf{S}^{\neq}\right)$are tabulated (Table-3).

Table-2: Concentrations of Periodate Species at Different Concentrations of Alkali

\begin{tabular}{c|c|c}
\hline$\left[\mathrm{OH}^{-}\right] \mathrm{M}$ & {$\left[\mathrm{H}_{2} \mathrm{IO}_{6}^{3-}\right] \mathrm{M}$} & {$\left[\mathrm{H}_{3} \mathrm{IO}_{6}^{2-}\right] \mathrm{M}$} \\
\hline 0.025 & 0.000107 & 0.000364 \\
\hline 0.05 & 0.000180 & 0.000308 \\
\hline 0.10 & 0.000267 & 0.000228 \\
\hline 0.20 & 0.000349 & 0.000149 \\
\hline 0.50 & 0.000427 & 0.000073 \\
\hline
\end{tabular}

Table-3: Arrhenius Parameters at $308 \mathrm{~K}$

\begin{tabular}{c|c|c|c|c}
\hline$\Delta \mathrm{E}^{\neq}$ & $\Delta \mathrm{H}^{\neq}$ & $-\Delta \mathrm{S}^{\neq}$ & $\log _{10} \mathrm{P}_{\mathrm{Z}}$ & $\begin{array}{c}\Delta \mathrm{G}^{\neq} \\
\mathrm{KJ} / \mathrm{mole}\end{array}$ \\
\hline 73.26 & $\mathrm{KJ} /$ mole & $\mathrm{J} / \mathrm{K} /$ mole & 8.32 & 99.75 \\
\hline
\end{tabular}

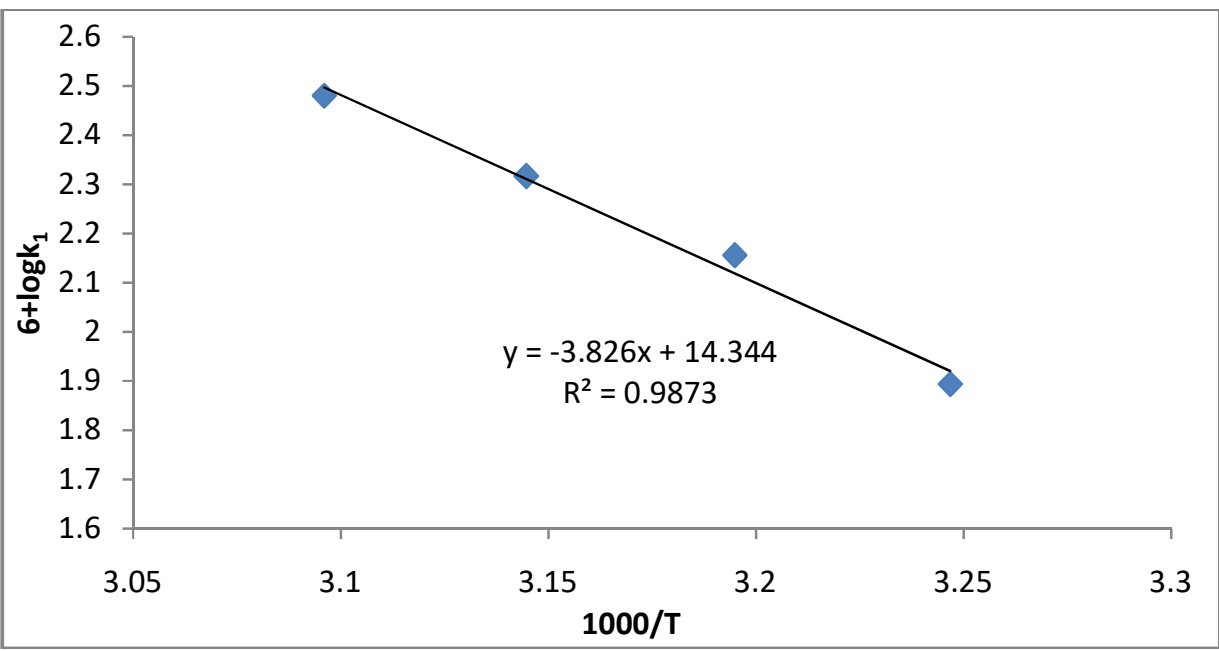

\section{Effect of Boric Acid and Salts}

Fig.-3:Effect of Temperature on Oxidation of PEG-200 by Periodate

Previous reports show that the addition of boric acid increased the rate in alkali medium as the conditions favor to form a complex between sugar alcohols (inositol/sorbitol/ mannitol) and borate ion ${ }^{24,25}$. It competeswiththe formation of a stable complex between sugar alcohol and periodate. And hence, substrate inhibition was explained in those cases. But, in the present case, boric acid addition didn't affect the reaction rate (Table-1).Each PEG-200 molecule has a good number of hydroxyl groups as the hydroxyl value of it ranges ${ }^{33}$ from 500 to 550. Hence, some of the hydroxyl groupson PEG-200 are engaged in complex formation with the highly dissociating potassium borate and leaving behind the other free hydroxyl groups on substrate. Addition of halides (chloride and iodide ions) decreased the rate of reaction but its effect is scanty in the case of bromide ions addition.

\section{Reaction and Rate Law}

The end products were identifiedby spot tests ${ }^{34}$. Long-chain aldehydes are the leading reaction products with a minor amount of carboxylic acids due to complete oxidation. Formation of aldehydes was confirmed via their transformation into 2,4-dinitrophenyldrazone derivatives. Nature of products formed in the present study corroborates with the previous reports ${ }^{16,36}$.End hydroxyl groups of these polymers exhibit a substantial effect on their physical as well as chemical properties. Hence, they are popularly 
RASĀYAN J. Chem.

Vol. 12 | No. 4 |1681 - 1687| October - December | 2019

known as polyethylene glycols instead of their technical name'polyethylene oxides ${ }^{35}$. Moreover, they have high hydroxyl values. Therefore, end hydroxyl groups were oxidized to result inthe observed products. However, unable to determine the exact stoichiometry in the present study. Based on the aboveobserved orders on the reactants, a rate law is proposed as given below:

$$
\begin{array}{llll}
\mathrm{H}_{3} \mathrm{IO}_{6}^{2-}+\text { PEG-200 } & \stackrel{\mathrm{K}_{4}}{\rightleftharpoons} \text { ComplexC }_{1} & \stackrel{\mathrm{k}_{1}}{\longrightarrow} & \text { Products } \\
\mathrm{H}_{2} \mathrm{IO}_{6}^{3-}+\text { PEG-200 } & \stackrel{\mathrm{K}_{2}}{\longrightarrow} & \text { Products }
\end{array}
$$

Since, the $\left[\mathrm{IO}_{4}{ }^{-}\right]$and $\left[\mathrm{H}_{2} \mathrm{I}_{2} \mathrm{O}_{10}{ }^{4}\right]$ are negligible, the total concentration of periodate can be written as

$$
\begin{aligned}
{\left[\mathrm{IO}_{4}^{-}\right]_{\mathrm{T}}=} & {\left[\mathrm{H}_{3} \mathrm{IO}_{6}^{2-}\right]+\left[\mathrm{H}_{2} \mathrm{IO}_{6}^{3-}\right]+\left[\text { Complex } \mathrm{C}_{1}\right]+\left[\text { Complex } \mathrm{C}_{2}\right] } \\
= & \mathrm{K}_{2}\left[\mathrm{IO}_{4}^{-}\right]\left[\mathrm{OH}^{-}\right]+\mathrm{K}_{3}\left[\mathrm{IO}_{4}^{-}\right]\left[\mathrm{OH}^{-}\right]^{2} \\
& +\mathrm{K}_{2} \mathrm{~K}_{4}[\mathrm{PEG}-200]\left[\mathrm{IO}_{4}^{-}\right]\left[\mathrm{OH}^{-}\right]+\mathrm{K}_{3} \mathrm{~K}_{5}[\mathrm{PEG}-200]\left[\mathrm{IO}_{4}^{-}\right]\left[\mathrm{OH}^{-}\right]^{2}
\end{aligned}
$$

Each PEG-200 molecule has a good number of hydroxyl groups as the hydroxyl value $\mathrm{e}^{33}$ of it ranges from 500 to 550 . Therefore, almost all reactive oxidant species $\left(\mathrm{H}_{3} \mathrm{IO}_{6}{ }^{2-}\right.$ and $\left.\mathrm{H}_{2} \mathrm{IO}_{6}{ }^{3-}\right)$ complex with hydroxyl groups available on PEG-200 and no free oxidant species will be available. Hence, the first two terms in the above equation can be neglected. Hence, we can write the above equation as:

$$
\begin{aligned}
& {\left[\mathrm{IO}_{4}^{-}\right]_{\mathrm{T}}=\mathrm{K}_{2} \mathrm{~K}_{4}[\mathrm{PEG}-200]\left[\mathrm{IO}_{4}^{-}\right]\left[\mathrm{OH}^{-}\right]+\mathrm{K}_{3} \mathrm{~K}_{5}[\mathrm{PEG}-200]\left[\mathrm{IO}_{4}^{-}\right]\left[\mathrm{OH}^{-}\right]^{2}} \\
& {\left[\mathrm{IO}_{4}^{-}\right]=\frac{\left[\mathrm{IO}_{4}^{-}\right]_{\mathrm{T}}}{\left[\mathrm{OH}^{-}\right][\mathrm{PEG}-200]\left\{\mathrm{K}_{2} \mathrm{~K}_{4}+\mathrm{K}_{3} \mathrm{~K}_{5}\left[\mathrm{OH}^{-}\right]\right\}}} \\
& \text {Rate }=\mathrm{k}_{1}\left[\text { Complex } \mathrm{C}_{1}\right]+\mathrm{k}_{2}\left[\text { Complex } \mathrm{C}_{2}\right] \\
& \text { Rate } \left.=\mathrm{k}_{1}\left[\text { Complex } \mathrm{C}_{1}\right]+\mathrm{k}_{2} \text { [Complex } \mathrm{C}_{2}\right] \\
& =k_{1} K_{4}\left[\mathrm{H}_{3} \mathrm{IO}_{6}^{2-}\right][\mathrm{PEG}-200]+k_{2} K_{5}\left[\mathrm{H}_{2} \mathrm{IO}_{6}^{3-}\right][\mathrm{PEG}-200] \\
& =\mathrm{k}_{1} \mathrm{~K}_{2} \mathrm{~K}_{4}\left[\mathrm{IO}_{4}^{-}\right]\left[\mathrm{OH}^{-}\right][\mathrm{PEG}-200]+\mathrm{k}_{2} \mathrm{~K}_{3} \mathrm{~K}_{5}\left[\mathrm{IO}_{4}^{-}\right]\left[\mathrm{OH}^{-}\right]^{2} \text { [PEG-200] } \\
& =\left[\mathrm{IO}_{4}^{-}\right]\left[\mathrm{OH}^{-}\right][\mathrm{PEG}-200]\left\{\mathrm{k}_{1} \mathrm{~K}_{2} \mathrm{~K}_{4}+\mathrm{k}_{2} \mathrm{~K}_{3} \mathrm{~K}_{5}\left[\mathrm{OH}^{-}\right]\right\} \\
& =\frac{\left[\mathrm{IO}_{4}^{-}\right]_{\mathrm{T}}[\mathrm{PEG}-200]\left\{k_{1} K_{2} K_{4}+k_{2} K_{3} K_{5}\left[\mathrm{OH}^{-}\right]\right\}}{[\mathrm{PEG}-200]\left\{\mathrm{K}_{2} \mathrm{~K}_{4}+\mathrm{K}_{3} \mathrm{~K}_{5}\left[\mathrm{OH}^{-}\right]\right\}} \\
& =\frac{\left[\mathrm{IO}_{4}^{-}\right]_{\mathrm{T}}\left\{k_{1} K_{2} K_{4}+k_{2} K_{3} K_{5}\left[\mathrm{OH}^{-}\right]\right\}}{\left\{\mathrm{K}_{2} \mathrm{~K}_{4}+\mathrm{K}_{3} \mathrm{~K}_{5}\left[\mathrm{OH}^{-}\right]\right\}}
\end{aligned}
$$

The above equation explains first and zero orders of reaction in [oxidant] and [PEG-200] respectively. As $\mathrm{k}_{2}<<1,\left[\mathrm{OH}^{-}\right]$in the numerator value is lower compared to that of the denominator. Hence, it also explains the inverse fractional value of order w.r.t. alkali concentration. Various methods available to understand the chemistry of pharmaceutical compounds ${ }^{37,38}$ and kinetic methods help to realize the mechanism involved in the oxidation of biologically important molecules ${ }^{39,40}$. Hence, the present study is an effort for the applicability of kinetic methods to know more about the stability and mechanism involved in the oxidation of pharmaceutically important PEG-200 by periodate.

\section{CONCLUSION}

Pharmaceutically and industrially important PEG-200 was subjected to oxidation by potassium periodate in alkaline medium. A suitable rate law is postulatedby taking into consideration of experimental results.

\section{ACKNOWLEDGMENT}

KVSK is thankful to UGC - New Delhi for financial support in the form of Minor Research Project, F.No.4-4/2015-15(MRP-SEM/UGC-SERO), November 2014. 
RASĀYAN J. Chem.

Vol. 12 | No. 4 |1681 - 1687| October - December | 2019

\section{REFERENCES}

1. A. Kolate, D. Baradia, S. Patil, I. Vhora, G. Kore, A. Misra, J. Controlled Release,192, 67(2014), DOI:10.1016/j.jconrel.2014.06.046

2. A.Thomas, S.S. Müller, H.Frey, Biomacromolecules, 15, 1935(2014), DOI:10.1021/bm5002608

3. A. A. D'souza, R. Shegokar, Expert Opin. Drug Delivery, 13, 1257(2016), DOI: $10.1080 / 17425247.2016 .1182485$

4. K. J. Laidler, Text book of 'Chemical Kinetics, Third Ed., Pearson Education Company, Singapore, (2004).

5. R. VenkataNadh, B. SyamaSundar, P.S. Radhakrishnamurti, Asian J. Chem., 9, 515(1997).

6. R. VenkataNadh, B. SyamaSundar, P.S. Radhakrishnamurti,J. Indian Chem. Soc., 76, 75(1999).

7. R. VenkataNadh, B. SyamaSundar, P.S. Radhakrishnamurti,Russ. J. Phys. Chem. A., 90, 1760(2016), DOI: $10.1134 / \mathrm{S} 0036024416090296$

8. R. VenkataNadh, B. SyamaSundar, P.S. Radhakrishnamurti,Oxid. Commun., 28, 81(2005).

9. Y.L.Kumar, R. VenkataNadh, P.S. Radhakrishnamurti, Russ. J. Phys. Chem. A., 90, 552(2016), DOI: $10.1134 / \mathrm{S} 0036024416030237$

10. Y.L.Kumar, R. VenkataNadh, P.S. Radhakrishnamurti, Russ. J. Phys. Chem. A., 90, 300(2016), DOI: $10.1134 / \mathrm{S} 0036024416020163$

11. Y.L.Kumar, R. VenkataNadh, P.S. Radhakrishnamurti, Russ. J. Phys. Chem. A., 89, 376(2015), DOI: $10.1134 / \mathrm{S} 0036024415030176$

12. Y.L.Kumar, R. VenkataNadh, P.S. Radhakrishnamurti, Bull. Chem. Soc. Ethiop., 29, 1(2015), DOI: $10.4314 /$ bcse.v29i1.12

13. R. VenkataNadh, B. SyamaSundar, P.S. Radhakrishnamurti, Russ. J. Phys. Chem. A., 75, 174(2001).

14. R. VenkataNadh, B. SyamaSundar, P. S. Radhakrishnamurti, Oxid. Commun., 21, 369(1998).

15. R. VenkataNadh, B. SyamaSundar, P. S. Radhakrishnamurti, Oxid. Commun., 23, 102(2000).

16. J. K. Szymański, F. Temprano-Coleto, J. Pérez-Mercader, Phys.Chem.Chem.Phys.,17, 6713(2015), DOI: $10.1039 / \mathrm{C} 4 \mathrm{CP} 05693 \mathrm{~K}$

17. S. Nagarajan, K. S. V. Srinivasan, K. VenkataRao, Polym. J., 26, 851(1994), DOI: $10.1295 /$ polymj. 26.851

18. X. Chen, L. J. Gao, F. Gu, Adv. Mater. Res.,1033, 382(2014), DOI: 10.4028/www.scientific.net/AMR.1033-1034.382

19. J. Prousek, I. Duriskova, Chem.Listy.,92, 198(1998).

20. W. Luo, L. Zhu, N. Wang, H. Tang, M. Cao, Y.She, Env. Sc. Tech., 44, 1786(2010), DOI: $10.1021 / \mathrm{es} 903390 \mathrm{~g}$

21. S.Imamura, M.Nakamura, N.Kawabata, J. Yoshida, S. Ishida, Ind. Eng. Chem. Prod. Res. Dev., 25, 34(1986), DOI: 10.1021/i300021a009

22. B. S. Lele, M. G. Kulkarni, J. Appl. Polym. Sci.,70, 883(1998), DOI:10.1002/(SICI)10974628(19981031)70:5<883::AID-APP7>3.0.CO;2-P

23. R. Hassan, S. Ibrahim, S. Sayed, Int. J. Chem. Kinet., 50, 775(2018), DOI:10.1002/kin.21212

24. Y.L.Kumar, R. VenkataNadh, P.S. Radhakrishnamurti, Asian J. Chem., 24, 5869(2012).

25. Y.L.Kumar, R. VenkataNadh, P.S. Radhakrishnamurti, Russ. J. Phys. Chem. A., 88, 780(2014), DOI: $10.1134 / \mathrm{S} 003602441405015 \mathrm{X}$

26. J.Aveston, J. Chem. Soc. A, 273(1969)

27. C.E.Crouthamel, A.M. Hayes, D.S. Martin, J. Am. Chem. Soc., 73, 82(1951), DOI: $10.1021 / \mathrm{ja} 01145 \mathrm{a} 030$

28. S.M.Tuwar, S.T. Nandibewoor, J.R. Raju, J. Indian. Chem. Soc., 69, 651(1992).

29. J.H. Shan, S.M. Li, S.Y. Huo, S.G. Shen, H.W. Sun, J. Iran. Chem. Soc., 2, 226 (2005), DOI: 10.1007/BF03245926

30. S.D. Kulkarni, S.T. Nandibewor, Transition Met. Chem., 31, 1034 (2006), DOI: 10.1007/s11243006-0103-4.

31. H. Shan, H.Y. Wang, C.Y. Song, F. Wang, J. Iran. Chem. Soc., 6, 393 (2009), DOI: 10.1007/BF03245849. 
RASĀYAN J. Chem.

Vol. 12 | No. 4 |1681 - 1687| October - December | 2019

32. W.F.K. Wynes-Jones, H. Eyring, J. Chem. Phys., 3, 492(1935).

33. https://onlinelibrary.wiley.com/doi/pdf/10.1002/3527600418.mb2532268kske0010

34. F. Feigl, Spot Tests in Organic Analysis, Elsevier Publishing Co., New York, 208 (1956).

35. T. Henning, J. SÖFW ., 127, 28(2001).

36. K.V.S KoteswaraRao, R.VenkataNadh,K. VenkataRatnam, Int. J. Res. Pharm. Sci.,10, 1(2019), DOI: 10.26452/ijrps.v10i4

37. K.K. Kumar, R.V. Nadh, Rasayan J. Chem., 4, 863(2011).

38. P. Senthikumar, S.S. Dawn, C.SaiPriya, A.V.Samrot, Rasayan J. Chem., 11, 1686(2018), DOI: $10.31788 /$ RJC.2018.1144053

39. V. Devra, M.B. Yadav, Rasayan J. Chem., 5, 67(2012).

40. S.E. Ashoor, F.M. Ashoor, N.Y.Salman, Rasayan J. Chem., 6, 1(2013).

[RJC-5433/2019] 